\title{
Zinc Transporters, Mechanisms of Action and Therapeutic Utility: Implications for Type 2 Diabetes Mellitus
}

\author{
Stephen A. Myers, ${ }^{1,2}$ Alex Nield, ${ }^{1}$ and Mark Myers ${ }^{1}$ \\ ${ }^{1}$ School of Health Sciences, University of Ballarat, University Drive, Mount Helen, VIC 3350, Australia \\ ${ }^{2}$ Collaborative Research Network, University of Ballarat, Mount Helen, VIC 3350, Australia \\ Correspondence should be addressed to Stephen A. Myers, s.myers@ballarat.edu.au
}

Received 4 September 2012; Revised 7 November 2012; Accepted 7 November 2012

Academic Editor: Samir Samman

Copyright ( 92012 Stephen A. Myers et al. This is an open access article distributed under the Creative Commons Attribution License, which permits unrestricted use, distribution, and reproduction in any medium, provided the original work is properly cited.

\begin{abstract}
Zinc is an essential trace element that plays a vital role in maintaining many biological processes and cellular homeostasis. Dysfunctional zinc signaling is associated with a number of chronic disease states including cancer, cardiovascular disease, Alzheimer's disease, and diabetes. Cellular homeostasis requires mechanisms that tightly control the uptake, storage, and distribution of zinc. This is achieved through the coordinated actions of zinc transporters and metallothioneins. Evidence on the role of these proteins in type 2 diabetes mellitus (T2DM) is now emerging. Zinc plays a key role in the synthesis, secretion and action of insulin in both physiological and pathophysiological states. Moreover, recent studies highlight zinc's dynamic role as a "cellular second messenger" in the control of insulin signaling and glucose homeostasis. This suggests that zinc plays an unidentified role as a novel second messenger that augments insulin activity. This previously unexplored concept would raise a whole new area of research into the pathophysiology of insulin resistance and introduce a new class of drug target with utility for diabetes pharmacotherapy.
\end{abstract}

\section{Introduction}

Type 2 diabetes mellitus (T2DM) is a progressive and debilitating disorder characterized by a loss of glycaemic control and metabolic homeostasis through the deterioration of beta cell function [1] and relative insulin deficiency and insulin resistance [2] in peripheral tissues including skeletal muscle, adipose, and liver [3]. The prevalence of this metabolic disorder is expected to increase from 171 million people in 2000 to 366 million in 2030, predominately due to changes in nutrition, reduced physical activity, and obesity [4]. Complications arising from T2DM include renal failure [5], blindness [6], and dyslipidemia [7], and it is widely accepted to be a fundamental and foremost basis for cardiovascular disease [8]. Given this projection, T2DM is becoming a leading cause of morbidity and mortality that results in a significant reduction in quality of life and life expectancy [9].

Recent developments in our understanding of T2DM have been heightened by the potential relevance of dysfunctional zinc signaling in this disease. Indeed, the early seminal discovery that insulin crystals contain zinc [10] facilitated a supportive role for this cation in diabetes. Zinc is an essential trace element that is indispensable for its role in maintaining normal physiological function and cellular homeostasis [11, 12]. Disturbances in zinc homeostasis have been observed in diabetes $[9,13-18]$ and several other pathologies including cancer $[19,20]$, autoimmune disease $[21,22]$, cardiovascular disease $[11,13,23,24]$, and Alzheimer's disease [25, 26].

Zinc has three major biological roles: catalytic, structural and regulatory [27]. The catalytic and structural role of zinc is well recognized, and there are many noteworthy reviews on these functions ([28-31] and references therein). For example, zinc is a structural constituent in numerous proteins, including growth factors, cytokines, receptors, enzymes, and transcription factors belonging to cellular signaling pathways [30]. Moreover, it is implicated in numerous cellular processes as a cofactor for an estimated 3000 human proteins including enzymes, nuclear factors, and hormones [32].

Homeostatic mechanisms that modulate zinc absorption, distribution, cellular uptake, and excretion [27] are vital 
for maintaining cellular function. Zinc's fundamental and diverse role in many cellular processes requires that zinc delivery to tissues and cells, intracellular availability, and intracellular distribution are tightly controlled [33]. These processes are maintained through the coordinated orchestration of a diverse family of transport proteins that modulate the uptake, efflux, and compartmentalization of zinc [33]. In this context, 4 metallothioneins (MTs), 14 zinc importers (SLC39/ZIPs), and 10 zinc exporters (SLC30/ZnTs) have been described in mammals [34]. (Human zinc transporters are defined as SLC30A and SLC39A while rodent transporters are designated Slc30a and Slc39a. For brevity, species designations are not used in this paper and transporters will be defined as SLC39A/ZIP and SLC30A/ZnT. Present terminology and accession numbers can be obtained through the GenBank database, http://www.ncbi.nlm.nih.gov/genbank). The MTs are the major zinc-binding proteins in mammalian systems that play an important regulatory role in zinc uptake, storage, release, and distribution [35, 36]. The zinc transporters are essential for preserving zinc homeostasis where the ZIP transporters contribute to a net increase in cytosolic zinc while the ZnTs cause a net decrease in cytosolic zinc [30] (Figure 1).

In the context of T2DM, essential dietary zinc and proteins that modulate zinc metabolism play a major role in metabolic homeostasis in peripheral tissues that respond to insulin. However, our understanding of the relationships between zinc transport, cellular zinc signaling, and T2DM is limited. Accordingly, this paper aims to delineate the role of zinc transporter systems, their mechanisms of action, and possible roles in disease with a particular focus on T2DM.

\section{Zinc and Zinc Transporters: Regulation, Signaling, and Cellular Mechanisms}

There is approximately $2-4 \mathrm{~g}$ of zinc in the human body but the concentration of the mobile pool of zinc ions in plasma is only $12-16 \mu \mathrm{M}[9]$. Given the low plasma concentration of zinc and its importance in cellular processes, it is essential that the availability and distribution of "free zinc" ("free zinc" is an operative term that is used to differentiate the zinc that is implicated in signaling transduction from that of zinc tightly bound to protein and thermodynamically unavailable) is tightly controlled [37]. Diet replenishes approximately $1 \%$ of the total body zinc lost by intestinal excretion in humans which is principally achieved by intestinal absorption [33]. Zinc delivery to tissues and cells and its intracellular distribution is also tightly regulated by a family of proteins that control uptake, efflux, and compartmentalization of zinc. In mammals, this is accomplished by an array of zinc transporters encoded by at least 27 genes from 3 families. These are the SLC30 (CDF/ZnT: vertebrate cation diffusion facilitator family proteins), SLC39 (ZIP: Zrt-,Irtlike Proteins) solute transporters, and the zinc-sensitizing MTs $[18,20,34,38-40]$ (Figure 1). The MTs play an important regulatory role in zinc uptake, storage, distribution, and release $[29,36]$. The ZIP family members facilitate the influx of zinc into the cytosol from the outside of the cells and from the lumen of intracellular compartments, while the ZnT family members enable the transport of zinc out of the cytosol into the lumen of intracellular organelles or to the outside of the cell $[27,34,40,41]$. Both ZIP and ZnT transporters work in an opposite but coordinated way to maintain cellular zinc homeostasis. Although the tissue distribution of the ZIP and ZnT family has been investigated in detail [42] (Table 1), in addition to differential expression based on gender [43], their mechanisms of action are still not well understood.

2.1. The SLC39/ZIP Family. ZIP transporters were first identified as "Zrt-, Irt-like Proteins" following their identification in yeast Saccharomyces cerevisiae (Zrt; zinc regulated transporter) and their similarity to the $\mathrm{Fe}(\mathrm{II})$ transporter Irt1 protein from the plant Arabidopsis thaliana [44, 45]. In these studies, Zhao and Eide [44] showed that overexpression of Zrt1 in yeast cells increased high affinity uptake of ${ }^{65} \mathrm{Zn}$ and that this was reduced in Zrtl mutant cells resulting in poor growth in zinc-limited media. Since their discovery, the ZIP family of proteins has grown to more than 100 members including those from insects, bacteria, nematodes and mammals [38, 46]. In mammals, members of this family are designated SLC39 for solute carrier [40]. Most ZIP transporters are predicted to have eight transmembrane (TMD) domains and similar predicted topologies (Figure 1). Characteristics of this topology have been confirmed for yeast [47]. Many of the family members have a long loop region between TMD III and IV that frequently contains a histidine-rich region $\left[\left(\mathrm{HX}_{n}, n=3\right.\right.$ to 5$\left.)\right]$ [40] that is suggested to be a putative zinc-binding domain [48]. The majority of ZIP proteins share a similar predicted topology where both the $\mathrm{N}$ and C-termini are extracytoplasmic [40]. A key feature of ZIP transporters is that they facilitate the influx of zinc into the cytosol from the extracellular space and from the lumen of intracellular compartments into the cytoplasm [30].

2.2. SLC30/ZnT Family. The first ZnT protein (termed ZnT1) was described by Palmiter and Findley [49]. ZnT1 was isolated from a rat kidney cDNA library and shown to restore zinc resistance when transfected into a zinc sensitive baby kidney hamster (BHK) cell line under high levels of extracellular zinc [49]. To date, the mammalian SLC30 family code for ten zinc transporters (ZnTs), ZnT1-10 [50]. The ZnT family of zinc transporters enables the transport of zinc out of the cytosol into the lumen of intracellular organelles or to the outside of the cell $[27,34,40,41,51]$ (Figure 1). Most members of this family have six predicted transmembrane domains (TMDs) and are predicted to have cytoplasmic amino and carboxy termini (Figure 1). In addition, ZnTs characteristically harbour a long histidine-rich loop between TMD IV and $\mathrm{V}\left[\left(\mathrm{HX}_{n}, n=3\right.\right.$ to 6$\left.)\right]$ and, similar to the ZIPs, place this potential zinc-binding site in the cytosol [52]. An exception to this rule is the human ZnT5 transporter which is predicted to contain 15 TMDs [53] and ZnT6 which harbours a serine-rich loop between TMDs IV and V [54]. Most $\mathrm{ZnTs}$ form homodimers with the exception of ZnT5 and ZnT6 which interact to form heterodimers to transport 


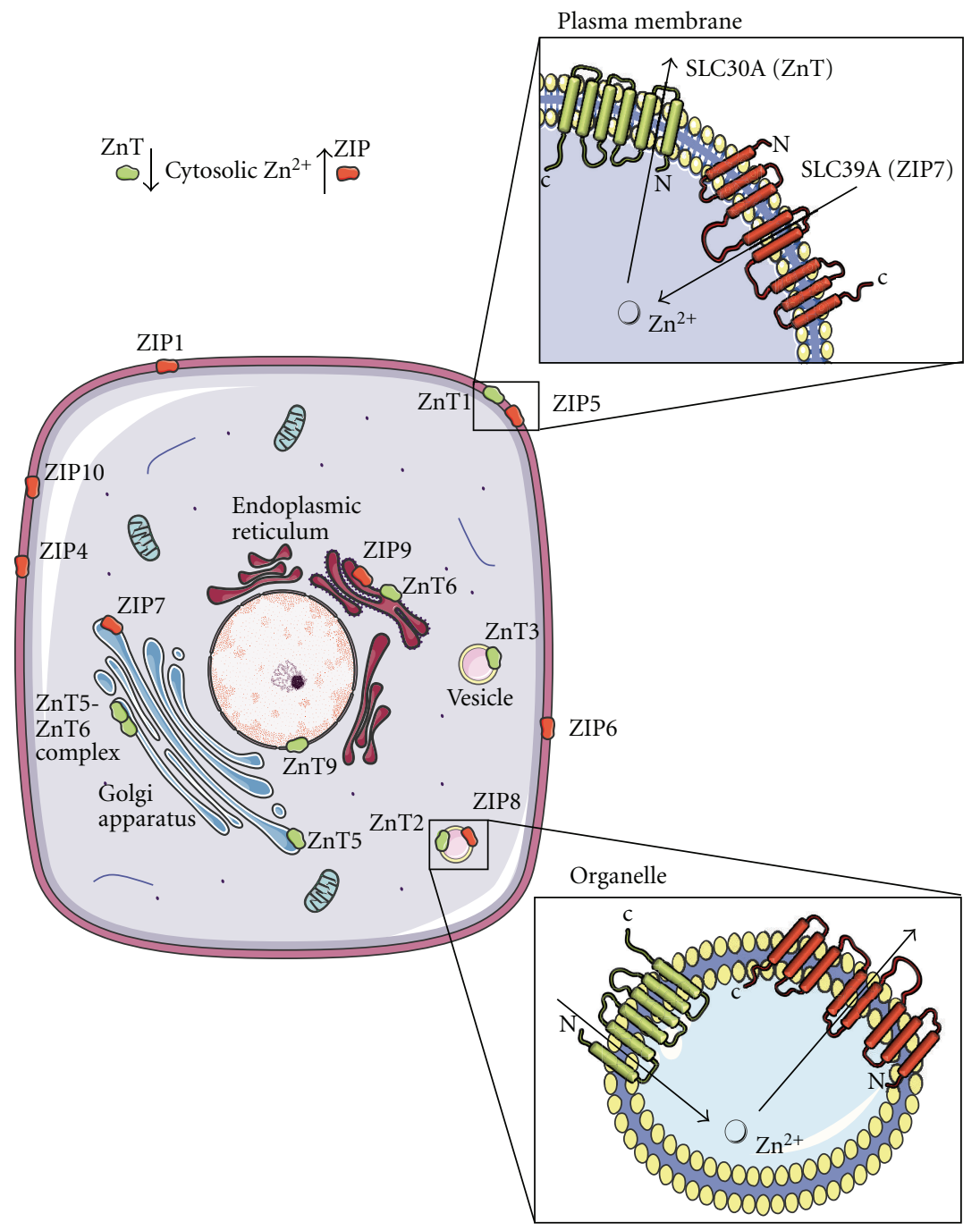

FIGURE 1: Subcellular localization and direction of transport of the zinc transporter families, ZnT and ZIP. Arrows show the direction of zinc mobilization for the ZnT (green) and ZIP (red) proteins. A net gain in cytosolic zinc is achieved by the transportation of zinc from the extracellular region and organelles such as the endoplasmic reticulum (ER) and Golgi apparatus by the ZIP transporters. Cytosolic zinc is mobilized into early secretory compartments such as the ER and Golgi apparatus by the ZnT transporters. Figures were produced using Servier Medical Art, http://www.servier.com/.

zinc into the early secretory pathway [55]. ZnT proteins have been identified in intracellular compartments that are usually associated with endosomes, Golgi apparatus, or the endoplasmic reticulum (Table 1) [56]. The tissue-specific expression of the ZnTs is varied with the exception of ZnT8 which is expressed predominately in insulin-producing beta cells of the pancreas $[57,58]$.

\section{Modes of Zinc Signaling, Zinc Transporters, and Insulin Signaling}

Zinc transporters typically act as zinc sensors, responding to zinc availability to maintain intracellular zinc homeostasis. The mode in which cellular homeostasis is achieved through zinc and zinc transporters is complex and comprehensive, and there are many significant reviews on these processes
$[3,26,30,33,34,38-40,50,56,104]$. Accordingly, the following section aims to briefly introduce a number of important concepts by which zinc and zinc transporters maintain cellular homeostasis and to highlight, where possible, the links between zinc transporter modulation and insulin signaling pathways.

3.1. Modes of Zinc Signaling. Given the large array of zinc transporters that are dedicated to controlling zinc homeostasis (Table 1), it is not surprising that this cation is quickly taking precedence as a leading signaling molecule analogous to calcium. In this context two modes of zinc signaling have been described: "early zinc signaling" (EZS) and "late zinc signaling" (LZS) [105, 106] (Figure 2). EZS involves a rapid change in intracellular levels of free zinc that occurs in minutes due to an extracellular stimulus that is transcription 
TABLE 1: Zinc transporters, cellular location, tissue-specific expression, and disease associations.

\begin{tabular}{|c|c|c|c|c|}
\hline Zinc transporter & Cellular localization & Tissue expression & Disease associations & References \\
\hline SLC39A1/ZIP1 & Plasma membrane & Ubiquitously expressed & Prostate cancer & [59-61] \\
\hline SLC39A2/ZIP2 & Plasma membrane & Blood, prostate & Carotid artery disease & {$[62-64]$} \\
\hline SLC39A3/ZIP3 & $\begin{array}{l}\text { Plasma membrane, intracellular } \\
\text { compartments }\end{array}$ & Mammary gland, prostate & Unknown & {$[60,65]$} \\
\hline SLC39A4/ZIP4 & Apical membranes & $\begin{array}{l}\text { Small intestine, stomach, colon, } \\
\text { kidney, brain }\end{array}$ & $\begin{array}{l}\text { Pancreatic cancer, acrodermatitis } \\
\text { enteropathica }(\mathrm{AE})\end{array}$ & {$[62,66,67]$} \\
\hline SLC39A5/ZIP5 & Basolateral membranes & $\begin{array}{l}\text { Pancreas, kidney, liver, spleen, } \\
\text { colon, stomach }\end{array}$ & Unknown & {$[68,69]$} \\
\hline SLC39A6/ZIP6 & Plasma membrane & Ubiquitously expressed & Breast cancer & {$[70]$} \\
\hline SLC39A7/ZIP7 & $\begin{array}{l}\text { Golgi apparatus, endoplasmic } \\
\text { reticulum }\end{array}$ & Ubiquitously expressed & Breast cancer & {$[71,72]$} \\
\hline SLC39A8/ZIP8 & Vesicles & Ubiquitously expressed & Unknown & {$[73,74]$} \\
\hline SLC39A9/ZIP9 & Trans-Golgi network & Ubiquitously expressed & Unknown & {$[75]$} \\
\hline SLC39A10/ZIP10 & Plasma membrane & Ubiquitously expressed & Breast cancer & {$[76,77]$} \\
\hline SLC39A11/ZIP11 & Unknown & Mammary gland & Unknown & {$[78]$} \\
\hline SLC39A12/ZIP12 & Unknown & Retina, brain, testis, lung & Schizophrenia & {$[79]$} \\
\hline SLC39A13/ZIP13 & Golgi apparatus & Ubiquitously expressed & Ehlers-Danlos syndrome & {$[80,81]$} \\
\hline SLC39A14/Zip14 & Plasma membrane & Ubiquitously expressed & Asthma & {$[82,83]$} \\
\hline SLC30A1/ZnT1 & Plasma membrane & Ubiquitously expressed & $\begin{array}{l}\text { Alzheimer's disease, Pancreatic } \\
\text { cancer }\end{array}$ & {$[19,25,49]$} \\
\hline SLC30A2/ZnT2 & Vesicles, lysosomes & $\begin{array}{l}\text { Pancreas, kidney, testis, epithelial } \\
\text { cells, small intestine }\end{array}$ & Unknown & {$[84]$} \\
\hline SLC30A3/ZnT3 & Synaptic vesicles & Brain, testis & Alzheimer's disease & {$[85,86]$} \\
\hline SLC30A4/ZnT4 & Intracellular compartments & $\begin{array}{l}\text { Mammary gland, brain, small } \\
\text { intestine, placenta, blood, } \\
\text { epithelial cells }\end{array}$ & Alzheimer's disease & {$[25,87]$} \\
\hline SLC30A5/ZnT5 & Secretory vesicles, Golgi apparatus & Ubiquitously expressed & Osteopenia & {$[53,88]$} \\
\hline SLC30A6/ZnT6 & Secretory vesicles, Golgi apparatus & $\begin{array}{l}\text { Small intestine, liver, brain, } \\
\text { adipose tissue }\end{array}$ & Alzheimer's disease & {$[25,54]$} \\
\hline SLC30A7/ZnT7 & Golgi apparatus & $\begin{array}{l}\text { Retina, small intestine, liver, } \\
\text { blood, epithelial cells, spleen }\end{array}$ & Prostate cancer & {$[89,90]$} \\
\hline SLC30A8/ZnT8 & Secretory vesicles & Pancreatic B-cells & Type 1 and 2 diabetes mellitus & {$[57,91,92]$} \\
\hline SLC30A9/ZnT9 & Cytoplasm, nucleus & Ubiquitously expressed & Unknown & {$[93]$} \\
\hline SLC30A10/ZnT10 & Unknown & Liver, brain & $\begin{array}{l}\text { Parkinson's disease, dystonia, } \\
\text { liver disease }\end{array}$ & [94-96] \\
\hline MT1 & Cytoplasm, nucleus, mitochondria & Ubiquitously expressed & Unknown & {$[97,98]$} \\
\hline MT2 & Cytoplasm, nucleus, mitochondria & Ubiquitously expressed & Unknown & {$[99,100]$} \\
\hline MT3 & Cytoplasm, nucleus & Brain, testis & Alzheimer's disease & {$[101]$} \\
\hline MT4 & Cytoplasm, nucleus & Squamous epithelia & Unknown & {$[102,103]$} \\
\hline
\end{tabular}

independent [30]. This was revealed in studies by Yamasaki et al. [105] who reported in mast cells a rapid increase in intracellular free zinc from the perinuclear region that includes the endoplasmic reticulum (ER) within minutes following extracellular stimulus with the high affinity IgE receptor (FcERI). These authors described this phenomenon as a "zinc wave" that is dependent on both calcium influx and MEK signaling, although calcium influx alone was not sufficient to induce the zinc wave while MEK activation was essential. LZS is also triggered by an extracellular signal and involves transcriptional-dependent changes in expression of proteins implicated in zinc homeostasis such as storage proteins or transporters [30, 106]. Both EZS and LZS modulate numerous cellular processes involved in cell differentiation, proliferation, and growth [35]. The importance of zinc for cell growth and proliferation is well recognized, and deficiencies in zinc cause growth retardation in all organisms investigated [35].

In 1980, Coulston and Dandona [107] discovered that zinc exerted a potent stimulatory effect upon lipogenesis in rat adipocytes independent of and additive to that of insulin. These findings suggested that the effects of this cation may have physiological relevance in controlling insulin signaling pathways since zinc is essential for the crystallization of 


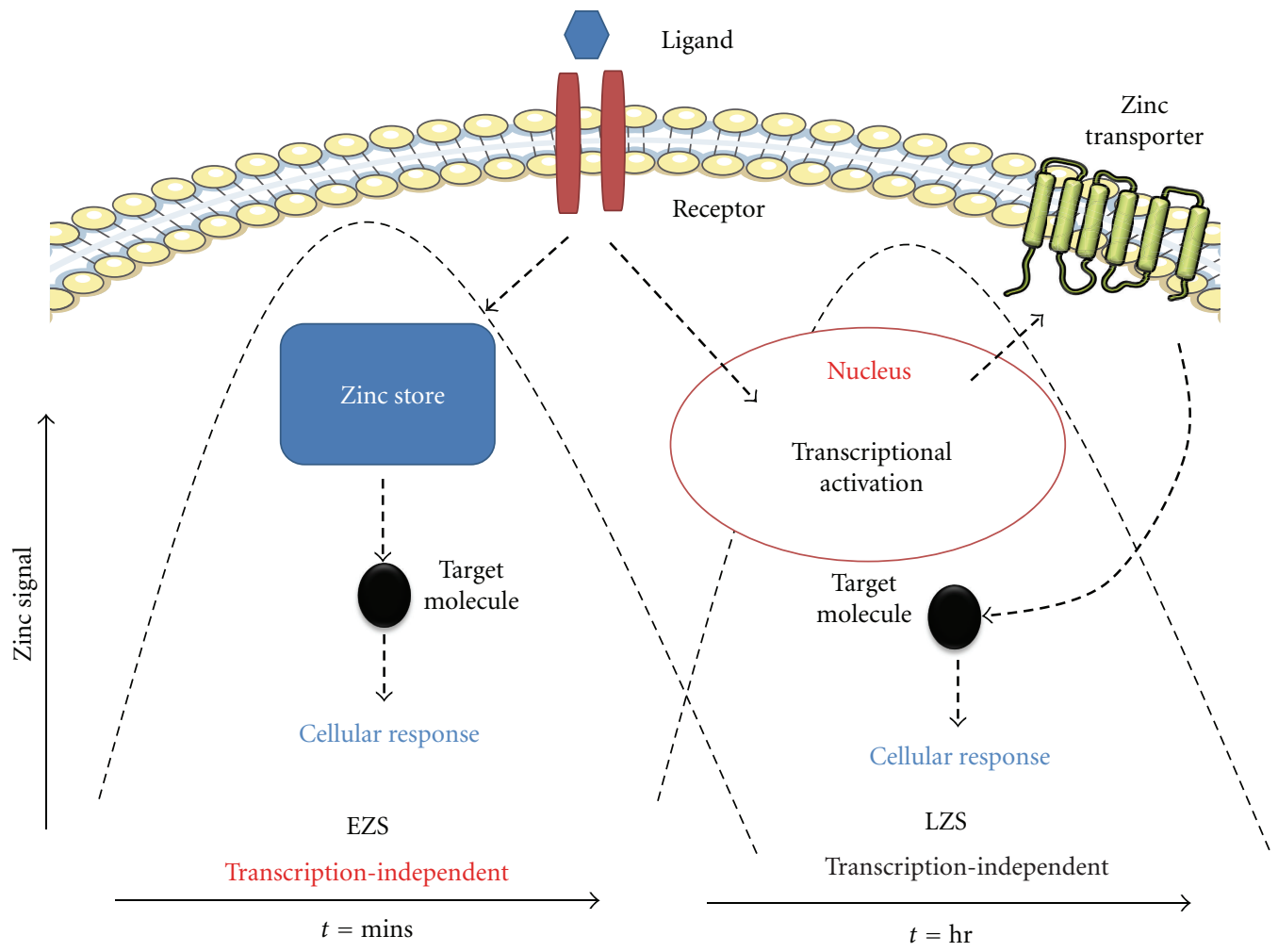

FIGURE 2: Early zinc signaling (EZS) and late zinc signaling (LZS). EZS involves transcription-independent mechanisms where an extracellular stimulus directly induces an increase in zinc levels within several minutes by releasing zinc from intracellular stores (e.g., endoplasmic reticulum). LSZ is induced several hours after an external stimulus and is dependent on transcriptional changes in zinc transporter expression. Components of this figure were produced using Servier Medical Art, http://www.servier.com/ and adapted from Fukada et al. [30].

insulin in hexameric complexes $[10,41]$ and is cosecreted with insulin on exposure to high glucose [41]. Similarly, May and Contoreggi [108], utilizing supraphysiological concentrations $(250-1000 \mu \mathrm{M})$ of $\mathrm{ZnCl}_{2}$, revealed a role for this cation in stimulating glucose transport and oxidation, incorporation of glucose carbon into glyceride-glycerol and glyceride-fatty acid, and inhibition of ritodrine-stimulated lipolysis in rat adipocytes. Equally, Ezaki [109] showed that rat adipocyte cells treated with $\mathrm{ZnSO}_{4}$ for 30 minutes stimulated cAMP phosphodiesterase and glucose transporter translocation from the intracellular region to the plasma membrane. Moreover, these authors proposed that this process was not dependent on insulin receptor stimulated kinase activity. This was in contrast to studies by Tang and Shay [110] who demonstrated that treatment of 3T3-L1 adipocytes over 5-10 minutes with $\mathrm{ZnCl}_{2}$ increased tyrosine phosphorylation of the IR- $\beta$ subunit of the insulin receptor and enhanced the transport of glucose in the absence of insulin through the PI-3-kinase signal transduction pathway. These studies have since been further delineated with investigations into the role of zinc as an inhibitor of protein tyrosine phosphatases $[51,105,111]$. In fact, inhibition of protein tyrosine phosphatase $1 \mathrm{~B}$ (PTP1B, a negative regulator of insulin signaling) activity ameliorates high-fat-dietinduced insulin resistance and lipid disorders in mice [112].
Furthermore, mice with a genetic ablation of PTP1B or pharmacological inhibition of its expression and activity are lean and have increased insulin sensitivity [113] and can restore insulin sensitivity in the liver of insulin receptor substrate 2-deficient mice [114].

Several groups have examined the mechanisms of the insulin-mimetic activity of zinc on glucose $[108,110,115-$ $119]$ and lipid $[107,119]$ metabolism. Cumulative evidence has revealed zinc as a direct signaling molecule implicated in extracellular signal recognition [105], second messenger metabolism [120], protein kinase activity [110], protein phosphorylation $[119,121]$, and the modulation of transcription factors [122] and highlights zinc's dynamic role as a "cellular second messenger" in the control of insulin signaling and glucose homeostasis [33, 105, 123]. Insulin is a critically important anabolic hormone implicated in maintaining normal physiological blood glucose. Zinc mediates these effects in part through the inhibition of protein tyrosine phosphatases which increase the net phosphorylation of the insulin receptor and activate its signaling cascade [51, 111]. Accordingly, the effects of zinc on cellular homeostasis appear to be numerous and include the stimulation of glucose uptake and lipogenesis in adipocytes [110], tyrosine phosphorylation of the insulin/IGF-1 receptor and insulin receptor substrate-1 $[51,111,121]$, activation of epidermal 
growth factor receptor $[72,121]$, inhibition of protein tyrosine phosphatase (PTP) $[33,111]$, and subsequent activation of mitogen-activated protein kinases (MAPKs) including extracellular-signal-regulated kinases 1 and 2 (ERK1/2), cJun N-terminal kinase (JNK) and p38 [20], and an increase in glycogen synthesis through the inhibition of glycogen synthase kinase-3 [115].

Several potential mechanisms have been suggested for the role of zinc affecting insulin action including the modulation of insulin receptor tyrosine kinase activity and subsequent defects in insulin-stimulated muscle glycogen synthesis [124, 125]. This raises the prospect that zinc plays a previously unidentified role as a novel second messenger that augments insulin activity. This concept raises a whole new area of research into the pathophysiology of insulin resistance and introduces a new class of drug target with utility for diabetes pharmacotherapy. However, the mechanistic details of how insulin affects intracellular zinc transport and the subsequent signaling cascades associated with glucose homeostasis and insulin resistance are yet to be defined.

3.2. Zinc and Zinc Transporters. The expression and cellular distribution of ZIPS and ZnTs are predominately (but not always) regulated by changes in extracellular and intracellular zinc concentrations [50]. The first study to delineate a role for zinc transporters and zinc homeostasis was performed in 1995 when Palmiter and Findley [49] isolated ZnT1 from a rat kidney cDNA expression library. These authors revealed that transfection of rat $\mathrm{ZnT} 1 \mathrm{cDNA}$ conferred resistance to high levels of extracellular zinc in the zinc-sensitive baby hamster kidney (BHK) cell line. Moreover, ZnT1 overexpression in the BHK cells increased ${ }^{65} \mathrm{Zn}$ efflux and reduced the intracellular steady-state concentration of zinc. Following these studies, in 1996 the second $\mathrm{ZnT}$ was isolated (ZnT2) (Palmiter et al. [84]). Similar to ZnT1, overexpression of rat ZnT2 cDNA conferred zinc resistance to BHK cells. However, unlike $\mathrm{ZnT1}$ which is located in the plasma membrane and lowers cellular zinc by stimulating cellular zinc efflux, ZnT2 is localized on vesicles and accumulates high concentrations of zinc in the endosomal/lysosomal compartment. ZnT2 is also associated with the inner mitochondrial membrane in mouse MEC mammary cells [126], and attenuation of ZnT2 mRNA expression reduced mitochondrial zinc uptake and mitochondrial zinc pools.

In studies on rats fed a diet low in zinc $(<1 \mathrm{mg} \mathrm{Zn} / \mathrm{Kg})$, low expression of ZnT2 was observed in the kidney and small intestine in comparison to rats fed an adequate intake of dietary zinc (30 $\mathrm{mg} \mathrm{Zn} / \mathrm{Kg}$ ) [127]. Likewise, ZnT1 and ZnT2 were markedly increased in these tissues when supplied with greater concentrations of dietary zinc $(180 \mathrm{mg} \mathrm{Zn/Kg})$ while ZnT4 was refractory to changes in zinc uptake. These findings suggested that a metal-responsive mode of regulation for at least ZnT1 and ZnT2 will involve metal-responsive elements (MREs) in the promoters of these genes. Indeed, the induction of the MTs by metals is mediated by several MREs located in the promoter region of MT genes that recruits the metal response-element transcriptional factor (MTF-1) and is responsible for its transcriptional regulation [128]. Studies in mouse embryo fibroblasts with homozygous deletions of the MTF-1 gene revealed that this protein was essential for basal and zinc-responsive regulation of ZnT1 [129]. MREs have been identified in the ZnT1 promoter [49], and ZnT5 has multiple metal-responsive elements (MREs) in its promoter region that mediate zinc-induced transcriptional activation $[40,130]$.

Many ZnT and ZIP transporters are also regulated by hormones or cytokines (see Lichten and Cousins [38] for a comprehensive review). In $\mathrm{LNCaP}$ and $\mathrm{PC}-3$ prostate cancer cells, ZIP1 is regulated by testosterone and prolactin and is consistent with the rapid cellular accumulation and uptake of zinc in these cells [131]. ZIP6 and ZIP14 mRNA expression respond to estrogen stimulation and have reduced response to tamoxifen or fulvestrant [132]. ZIP8 is strongly induced by TNF- $\alpha$ in primary human lung epithelial cells $[133,134]$ and A459 lung cancer cells [134] concomitant with an increase in intracellular zinc. Recent evidence suggests that the mechanism of TNF- $\alpha$ induction of ZIP8 is through the NF- $\kappa$ B pathway [134]. ZIP14 is upregulated by IL-6 (but not by TNF- $\alpha$ ) in mouse hepatocytes where it is suggested to play a role in hypozincemia that accompanies the acute phase response to inflammation and infection [135].

Some transporters alter their transcriptional and posttranscriptional expression in response to zinc fluctuations, while others alter their subcellular localization [33]. For example, ZnT1 is predominately localized to the plasma membrane but has recently been shown to locate to the endoplasmic reticulum complexed with EVER transmembrane channel-like proteins in human keratinocytes [136]. EVER and ZnT1 complexes influence intracellular zinc concentration and downregulate transcription factors stimulated by zinc (MTF-1) or cytokines (c-Jun and Elk). Similarly, Kim et al. [137] revealed that the transfection of human embryonic kidney (HEK293) cells with mZIP4 resulted in the localization of this transporter to cytoplasmic vesicles in the perinuclear region. Subsequent depletion of zinc from the HEK293 cells following treatment with the heavy metal chelator TPEN resulted in a redistribution of MZIP4 towards the plasma membrane. Equally, mZIP1 and mZIP3 were found to transit between the plasma membrane and intracellular compartments in zinc-depleted HEK293 cells [60].

$\mathrm{ZnT5}$ is located in the Golgi apparatus and facilitates the transport of zinc into the Golgi lumen for storage. Overexpression of ZnT5 in HeLa cells facilitates zinc uptake into intracellular vesicles suggesting that ZnT5 is capable of accumulating zinc in intracellular compartments [38]. Importantly, ZnT5 is thought to be responsible for loading zinc to secretory, membrane-bound, or organelle-resident proteins to facilitate biological activity of proteins [138]. An important component of ZnT5 as a Golgi zinc influx transporter is its critical role in counteracting the effects of Zip7 to maintain the balance of zinc mobilization between the Golgi and cytosol.

ZnT4 and ZnT6 have been shown to traffic from the trans-Golgi network to the cytoplasmic vesicular compartment with increasing concentrations of extracellular zinc in rat kidney cells [54]. In transient transfection experiments, Milon et al. [139] revealed that human ZIP1 (hZIP1) has 
vesicular localization in COS-7 cells. In contrast, transfection of hZIP1 into K562 cells showed plasma membrane localization and suggests that the localization for this protein is under the influence of zinc-responsive regulation. In HEK293 kidney cells grown in zinc-replete medium, mouse ZIP1 and ZIP3 (mZIP) were localized to intracellular organelles [60]; however in the absence of zinc, these proteins were preferentially localized to the plasma membrane suggesting that they are modulated at the posttranslational level to control zinc homeostasis [60].

Although many zinc transporters respond to fluctuating zinc levels and alter their subcellular localization, ZIP7 is an exception and is restricted constitutively to the membrane of the Golgi apparatus and endoplasmic reticulum [34]. Studies in human cells including lung fibroblasts (WI-38), prostate epithelial cells (RWPE1), erythroleukemia cells (K-562), and mammary gland epithelial cells (MCF-7) showed ZIP7 antibody fluorescence staining in the perinuclear region of the Golgi apparatus [71]. This was confirmed by treating MCF cells with brefeldin A, a fungal macrocyclic known to disrupt the Golgi apparatus, prior to immunofluorescent staining [71]. Furthermore, ZIP7 gene expression and intracellular location are not altered in response to changes in intracellular zinc status [71]. In this context, it is unlikely that ZIP7 is upregulated by cytosolic zinc concentrations. In contrast, ZIP7 has been shown to be regulated at the post-translational level by suppression of ZIP7 protein translation in response to high zinc concentrations [38, 71]. ZIP7 is involved in the release of zinc from intracellular stores and activation of multiple tyrosine kinases through zinc-mediated inactivation of protein phosphatases [20]. The presence of multiple MAPKbinding motifs and phosphorylation sites on the cytoplasmic domain of ZIP7 suggests that zinc transport by this protein is regulated by phosphorylation [20]. In a recent study, the phosphorylation of the endoplasmic reticulum ZIP7 by protein kinase CK2 was associated with the gated release of zinc from intracellular stores leading to activation of tyrosine kinases and the phosphorylation of AKT and extracellular signaling kinases 1 and 2 [140]. This raises an interesting mechanism for the regulation of ZIP7 through the activity of CK2 possibly through insulin-mediated signaling pathways. Interestingly, treatment of pancreatic beta cells with $100 \mathrm{nM}$ insulin over 4 hours resulted in a significant increase in CK2 kinase activity [141]; however the complete physiological importance of this effect is still to be elucidated.

It has been suggested that increased expression of ZIP7 could prolong growth factor signaling and contribute to dysfunctional regulatory mechanisms in a number of disease states characterized by the increased activation of tyrosine kinases [20]. Equally decreased expression of ZIP7 might contribute to a deactivation of signaling events associated with cellular signaling through constitutively activated protein phosphatases. Although there are several studies implicating increased protein-tyrosine phosphatase activity as contributing to insulin resistance $[51,110,111,113,114$, 121, 142-145], the evidence linking insulin signaling to zinc transport mechanisms and zinc-mediated signaling events is lacking.
3.3. Zinc Transporters and Zinc Signaling in T2DM. The interaction between zinc homeostasis and T2DM has been examined based on the insulinomimetic effect of zinc on insulin signaling. Our recent understanding of T2DM and the role that zinc signaling plays in maintaining cellular homeostasis has prompted intensive research efforts into dysregulated cellular zinc partitioning in this chronic disease. Given that health issues associated with T2DM have global significance, there is considerable interest in elucidating the molecular mechanisms responsible for insulin resistance and defects in glycaemic control. Zinc has an integral role in the processing, storage, secretion, and action of insulin in response to changes in elevated glucose concentrations [33, $118]$. In vivo, dietary zinc supplements given to $d b / d b$ mice attenuated hyperglycemia and hyperinsulinemia and elevated pancreatic zinc concentrations [117]. Moreover, zinc treatment significantly improved glucose clearance in genetically nonobese IDE-deficient diabetic rats and mice with concomitant diabetes and obesity $[123,146]$. In fact, zincdeficient animals are less sensitive to insulin [147], and oral administration of zinc in animals and humans improves glycaemic control in type 1 and type 2 diabetic patients [3]. In humans, Jansen et al. [9] found a significant reduction in plasma zinc levels in type 1 diabetes and T2DM patients compared to healthy controls and suggest that oral supplementation of zinc may qualify as a potential adjunct therapy in T2DM patients by promoting insulin signaling. A recent systemic review of the literature and meta-analysis on 25 studies reporting the effects of zinc supplementation on T2DM revealed that those patients receiving the zinc therapy had improved glycaemic control and health lipid parameters [148].

In the context of zinc transporter systems the most well studied in diabetes is $\mathrm{ZnT}$. In human type 1 diabetes, ZnT8 was targeted by autoantibodies in $60 \%-80 \%$ of new onset cases [149]. Recently ZnT8 is purported to have a role in T2DM. The expression of ZnT8 is predominately within the insulin-producing beta cells of the pancreas [57] but has also been identified at much lower levels in other tissues such as kidney and testis [42]. ZnT8 overexpression in INS-1 cells enhanced glucose-stimulated insulin secretion [57] and the downregulation of $\mathrm{ZnT} 8$ in this system showed reduced insulin content and secretion in response to a hyperglycaemic stimulus [150]. Mice with a targeted beta cell ZnT8 "knock out" display deficiencies in glucose intolerance [151]. Moreover, ZnT8 null mice display diet-dependent abnormalities in glucose tolerance [152], insulin secretion [152, 153], and body weight $[152,154]$.

Several genomewide association studies (GWASs) have implicated ZnT8 in T2DM in humans [8, 155-157]. Thus, having two copies of the at-risk polymorphic variant rs13266634, a nonsynonymous single nucleotide polymorphism (SNP) (Arg325Trp) in ZnT8 is associated with a 43\% increase risk of developing diabetes [158]. Recently a GWAS study identified variants in $\mathrm{ZnT} 8$ to be associated with a greater risk for T2DM from 1508 Chinese Han T2DM patients and 1500 age- and gender-matched healthy controls [156]. All subjects were genotyped for 3 tagging SNPs (rs2466295, rs4876703, rs11558471). The genotype and the 
allele distributions of the AA genotype of rs11558471 were more common in the T2DM subjects than the control group [156]. The frequency of the A-C-A haplotype was significantly greater in the T2DM subjects compared to the controls while the A-G-A haplotype was significantly reduced in the T2DM subjects compared to the controls. These authors predict that the A-C-A haplotype is a risk factor for T2DM while the A-G-A haplotype is protective for T2DM in Chinese Han people [156]. Accordingly, it is suggested that polymorphisms in ZnT8 affect insulin secretion and increase the risk for T2DM as binding of zinc is paramount for the crystallization of insulin [151, 152].

Several other zinc transporters, although not directly associated with diabetes, are implicated in insulin-mediated signaling and glycaemic control in animal models and humans. Huang et al. [159] demonstrated that overexpression of ZnT7 in pancreatic insulinoma RIN5mf cells increased insulin secretion upon glucose stimulation. Following these studies Huang et al. [160] revealed that ZnT7 knockout mice were more susceptible to diet-induced glucose intolerance and insulin resistance, and this was concomitant with a reduction in the mRNA expression of the insulin receptor, insulin receptor substrate 2, and Akt1 in primary skeletal myotubes. ZnT3, ZnT5, and ZnT8 gene expression is differentially regulated by glucose in INS-1E cells and ZnT3 knockdown decreased insulin gene expression and secretion and resulted in hyperglycemia in streptozotocin-treated ZnT3 null mice [161]. Similarly, elevated glucose concentrations increased free cytosolic zinc in mouse pancreatic islets and were associated with an increase in the mRNA expression of ZIP6-8 [162]. These authors suggested that glucose induces cytosolic zinc leading to the processing and storage of insulin and associated increase in the ZIP importers.

The studies presented on the role of zinc and zinc transporters in cell-based and rodent knockout and/or overexpression systems and allelic variants in humans suggest that this family of proteins plays a key role in the pathogenesis of diabetes. Identifying how zinc and zinc transporters play a role in insulin signaling and glycaemic control will be of upmost importance in elucidating novel therapeutic options for the treatment and prevention of T2DM.

\section{Conclusions and Perspectives}

Zinc is an essential trace metal that is implicated in many physiological and metabolic processes. The ubiquitous nature of zinc in physiological systems suggests that atypical levels are likely to have many biological and clinical effects. The true significance of zinc in cellular signaling is just emerging. In this context the zinc transporters play an essential role in insulin and glucose homeostasis. The inhibition of protein tyrosine phosphatases by zinc under physiological conditions involving zinc transporter mechanisms has widespread implications for understanding insulin resistance and disease progression. While a clear role for ZnT8 in insulin production and susceptibility to T2DM has been established, in the future, confirmation of a role for zinc transporters and zinc signaling in insulin activity will establish zinc homeostasis as a key element in the pathogenesis of T2DM.

\section{References}

[1] B. Charbonnel and B. Cariou, "Pharmacological management of type 2 diabetes: the potential of incretin-based therapies," Diabetes, Obesity and Metabolism, vol. 13, no. 2, pp. 99-117, 2011.

[2] E. E. Wright, A. H. Stonehouse, and R. M. Cuddihy, "In support of an early polypharmacy approach to the treatment of type 2 diabetes," Diabetes, Obesity and Metabolism, vol. 12, no. 11, pp. 929-940, 2010.

[3] J. Jansen, W. Karges, and L. Rink, "Zinc and diabetes-clinical links and molecular mechanisms," The Journal of Nutritional Biochemistry, vol. 20, no. 6, pp. 399-417, 2009.

[4] J. E. Shaw, R. A. Sicree, and P. Z. Zimmet, "Global estimates of the prevalence of diabetes for 2010 and 2030," Diabetes Research and Clinical Practice, vol. 87, no. 1, pp. 4-14, 2010.

[5] S. Youngman, "Diabetes and renal failure," in Advanced Renal Care, pp. 122-133, Blackwell Publishing, 2008.

[6] Y. Lin and Z. Sun, "Current views on type 2 diabetes," Journal of Endocrinology, vol. 204, no. 1, pp. 1-11, 2010.

[7] D. C. Patel, C. Albrecht, D. Pavitt et al., "Type 2 diabetes is associated with reduced ATP-binding cassette transporter A1 gene expression, protein and function," PLoS One, vol. 6, no. 7, Article ID e22142, 2011.

[8] U. J. Kommoju and B. M. Reddy, "Genetic etiology of type 2 diabetes mellitus: a review," International Journal of Diabetes in Developing Countries, vol. 31, pp. 51-64, 2011.

[9] J. Jansen, E. Rosenkranz, S. Overbeck et al., "Disturbed Zinc homeostasis in diabetic patients by in vitro and in vivo analysis of insulinomimetic activity of Zinc," The Journal of Nutritional Biochemistry, vol. 23, pp. 1458-1466, 2012.

[10] D. Scott, "Crystalline insulin," The Biochemical Journal, vol. 28, pp. 1592-1602, 1934.

[11] P. J. Little, R. Bhattacharya, A. E. Moreyra, and I. L. Korichneva, "Zinc and cardiovascular disease," Nutrition, vol. 26, no. 11-12, pp. 1050-1057, 2010.

[12] S. L. Kelleher, N. H. McCormick, V. Velasquez, and V. Lopez, "Zinc in specialized secretory tissues: roles in the pancreas, prostate, and mammary gland," Advances in Nutrition, vol. 2, pp. 101-111, 2011.

[13] N. Stadler, S. Heeneman, S. Voo et al., "Reduced metal ion concentrations in atherosclerotic plaques from subjects with type 2 diabetes mellitus," Atherosclerosis, vol. 222, pp. 512518, 2012.

[14] S. Ferdousi and A. R. Mia, "Serum levels of copper and Zinc in newly diagnosed type-2 diabetic subjects," Mymensingh Medical Journal, vol. 21, pp. 475-478, 2012.

[15] M. Basaki, M. Saeb, S. Nazifi, and H. A. Shamsaei, "Zinc, Copper, Iron, and Chromium concentrations in young patients with type 2 diabetes mellitus," Biological Trace Element Research, vol. 148, pp. 161-164, 2012.

[16] Y. Yoshikawa, H. Sakurai, and H. Yasui, "Challenge of studies on the development of new $\mathrm{Zn}$ complexes to treat diabetes mellitus," Journal of the Pharmaceutical Society of Japan, vol. 131, no. 6, pp. 925-930, 2011.

[17] S. Ruchi and K. Ashok, "A study of age related decrease in Zinc and Chromium and its correlations with type 2 diabetes mellitus," Research Journal of Chemistry and Environment, vol. 15, pp. 75-80, 2011. 
[18] J. Rungby, “Zinc, Zinc transporters and diabetes," Diabetologia, vol. 53, no. 8, pp. 1549-1551, 2010.

[19] A. K. Jayaraman and S. Jayaraman, "Increased level of exogenous Zinc induces cytotoxicity and up-regulates the expression of the ZnT-1 Zinc transporter gene in pancreatic cancer cells," The Journal of Nutritional Biochemistry, vol. 22, no. 1, pp. 79-88, 2011.

[20] C. Hogstrand, P. Kille, R. I. Nicholson, and K. M. Taylor, "Zinc transporters and cancer: a potential role for ZIP7 as a hub for tyrosine kinase activation," Trends in Molecular Medicine, vol. 15, no. 3, pp. 101-111, 2009.

[21] A. J. Delli, F. Vaziri-Sani, B. Lindblad et al., "Zinc transporter 8 autoantibodies and their association with SLC30A8 and HLA-DQ genes differ between immigrant and Swedish patients with newly diagnosed type 1 diabetes in the better diabetes diagnosis study," Diabetes, vol. 10, pp. 2556-2564, 2012.

[22] E. Kawasaki, K. Nakamura, G. Kuriya et al., "Differences in the humoral autoreactivity to Zinc transporter 8 between childhood- and adult-onset type 1 diabetes in Japanese patients," Clinical Immunology, vol. 138, no. 2, pp. 146-153, 2011.

[23] N. Patrushev, B. Seidel-Rogol, and G. Salazar, "Angiotensin II requires Zinc and downregulation of the Zinc transporters ZnT3 and ZnT10 to induce senescence of vascular smooth muscle cells," PLoS One, vol. 7, Article ID e33211, 2012.

[24] M. Foster and S. Samman, "Zinc and redox signaling: perturbations associated with cardiovascular disease and diabetes mellitus," Antioxidants \& Redox Signaling, vol. 13, no. 10, pp. 1549-1573, 2010.

[25] G. Lyubartseva, J. L. Smith, W. R. Markesbery, and M. A. Lovell, "Alterations of Zinc transporter proteins ZnT-1, ZnT4 and ZnT-6 in preclinical Alzheimer's disease brain," Brain Pathology, vol. 20, no. 2, pp. 343-350, 2010.

[26] C. Devirgiliis, P. D. Zalewski, G. Perozzi, and C. Murgia, "Zinc fluxes and Zinc transporter genes in chronic diseases," Mutation Research, vol. 622, no. 1-2, pp. 84-93, 2007.

[27] C. Chasapis, A. Loutsidou, C. Spiliopoulou, and M. Stefanidou, "Zinc and human health: an update," Archives of Toxicology, vol. 86, pp. 1-14, 2011.

[28] W. Maret, "Metals on the move: Zinc ions in cellular regulation and in the coordination dynamics of Zinc proteins," BioMetals, vol. 24, no. 3, pp. 411-418, 2011.

[29] W. Maret, "New perspectives of Zinc coordination environments in proteins," Journal of Inorganic Biochemistry, vol. 111, pp. 110-116, 2011.

[30] T. Fukada, S. Yamasaki, K. Nishida, M. Murakami, and T. Hirano, "Zinc homeostasis and signaling in health and diseases-Zinc signaling," Journal of Biological Inorganic Chemistry, vol. 16, pp. 1123-1134, 2011.

[31] M. Lu and D. Fu, "Structure of the Zinc transporter YiiP," Science, vol. 317, no. 5845, pp. 1746-1748, 2007.

[32] C. Andreini, L. Banci, I. Bertini, and A. Rosato, "Counting the Zinc-proteins encoded in the human genome," Journal of Proteome Research, vol. 5, no. 1, pp. 196-201, 2006.

[33] E. Mocchegiani, R. Giacconi, and M. Malavolta, "Zinc signalling and subcellular distribution: emerging targets in type 2 diabetes," Trends in Molecular Medicine, vol. 14, no. 10, pp. 419-428, 2008.

[34] T. Kambe, "An overview of a wide range of functions of $\mathrm{ZnT}$ and Zip Zinc transporters in the secretory pathway," Bioscience, Biotechnology and Biochemistry, vol. 75, no. 6, pp. 1036-1043, 2011.
[35] D. Beyersmann and H. Haase, "Functions of Zinc in signaling, proliferation and differentiation of mammalian cells," BioMetals, vol. 14, no. 3-4, pp. 331-341, 2001.

[36] M. Vašák and D. W. Hasler, "Metallothioneins: new functional and structural insights," Current Opinion in Chemical Biology, vol. 4, no. 2, pp. 177-183, 2000.

[37] H. Haase and L. Rink, Zinc Signaling. Zinc in Human Health, IOS Press, Amsterdam, Netherlands, 2011.

[38] L. A. Lichten and R. J. Cousins, "Mammalian Zinc transporters: nutritional and physiologic regulation," Annual Review of Nutrition, vol. 29, pp. 153-176, 2009.

[39] J. P. Liuzzi and R. J. Cousins, "Mammalian Zinc transporters," Annual Review of Nutrition, vol. 24, pp. 151-172, 2004.

[40] D. J. Eide, "Zinc transporters and the cellular trafficking of Zinc," Biochimica et Biophysica Acta, vol. 1763, no. 7, pp. 711722, 2006.

[41] A. B. Petersen, K. Smidt, N. E. Magnusson, F. Moore, L. Egefjord, and J. Rungby, "siRNA-mediated knock-down of ZnT3 and ZnT8 affects production and secretion of insulin and apoptosis in INS-1E cells," Acta Pathologica, Microbiologica et Immunologica Scandinavica, vol. 119, no. 2, pp. 93-102, 2011.

[42] M. Nishimura and S. Naito, "Tissue-specific mRNA expression profiles of human solute carrier transporter superfamilies," Drug Metabolism and Pharmacokinetics, vol. 23, no. 1, pp. 22-44, 2008.

[43] M. Foster, D. Hancock, P. Petocz, and S. Samman, "Zinc transporter genes are coordinately expressed in men and women independently of dietary or plasma Zinc," The Journal of Nutrition, vol. 141, no. 6, pp. 1195-1201, 2011.

[44] H. Zhao and D. Eide, "The yeast ZRT1 gene encodes the Zinc transporter protein of a high-affinity uptake system induced by Zinc limitation," Proceedings of the National Academy of Sciences of the United States of America, vol. 93, no. 6, pp. 2454-2458, 1996.

[45] D. Eide, M. Broderius, J. Fett, and M. L. Guerinot, "A novel iron-regulated metal transporter from plants identified by functional expression in yeast," Proceedings of the National Academy of Sciences of the United States of America, vol. 93, no. 11, pp. 5624-5628, 1996.

[46] D. J. Eide, "The SLC39 family of metal ion transporters," Pflügers Archiv, vol. 447, no. 5, pp. 796-800, 2004.

[47] R. S. Gitan, M. Shababi, M. Kramer, and D. J. Eide, "A cytosolic domain of the yeast Zrtl Zinc transporter is required for its post-translational inactivation in response to Zinc and cadmium," The Journal of Biological Chemistry, vol. 278, no. 41, pp. 39558-39564, 2003.

[48] X. Mao, B.-E. Kim, F. Wang, D. J. Eide, and M. J. Petris, "A histidine-rich cluster mediates the ubiquitination and degradation of the human Zinc transporter, hZIP4, and protects against Zinc cytotoxicity," The Journal of Biological Chemistry, vol. 282, no. 10, pp. 6992-7000, 2007.

[49] R. D. Palmiter and S. D. Findley, "Cloning and functional characterization of a mammalian Zinc transporter that confers resistance to Zinc," EMBO Journal, vol. 14, no. 4, pp. 639-649, 1995.

[50] I. Sekler, S. L. Sensi, M. Hershfinkel, and W. F. Silverman, "Mechanism and regulation of cellular Zinc transport," Molecular Medicine, vol. 13, no. 7-8, pp. 337-343, 2007.

[51] H. Haase and W. Maret, "Intracellular Zinc fluctuations modulate protein tyrosine phosphatase activity in insulin/ insulin-like growth factor-1 signaling," Experimental Cell Research, vol. 291, no. 2, pp. 289-298, 2003. 
[52] R. D. Palmiter and L. Huang, "Efflux and compartmentalization of Zinc by members of the SLC30 family of solute carriers," Pflügers Archiv, vol. 447, no. 5, pp. 744-751, 2004.

[53] T. Kambe, H. Narita, Y. Yamaguchi-Iwai et al., "Cloning and characterization of a novel mammalian Zinc transporter, Zinc transporter 5, abundantly expressed in pancreatic $\beta$ cells," The Journal of Biological Chemistry, vol. 277, no. 21, pp. 19049-19055, 2002.

[54] L. Huang, C. P. Kirschke, and J. Gitschier, "Functional characterization of a novel mammalian Zinc transporter, ZnT6," The Journal of Biological Chemistry, vol. 277, no. 29, pp. 26389-26395, 2002.

[55] A. Fukunaka, T. Suzuki, Y. Kurokawa et al., "Demonstration and characterization of the heterodimerization of ZnT5 and ZnT6 in the early secretory pathway," The Journal of Biological Chemistry, vol. 284, no. 45, pp. 30798-30806, 2009.

[56] R. J. Cousins, J. P. Liuzzi, and L. A. Lichten, "Mammalian Zinc transport, trafficking, and signals," The Journal of Biological Chemistry, vol. 281, no. 34, pp. 24085-24089, 2006.

[57] F. Chimienti, S. Devergnas, F. Pattou et al., "In vivo expression and functional characterization of the Zinc transporter ZnT8 in glucose-induced insulin secretion," Journal of Cell Science, vol. 119, no. 20, pp. 4199-4206, 2006.

[58] D. Mohanasundaram, C. Drogemuller, J. Brealey et al., "Ultrastructural analysis, Zinc transporters, glucose transporters and hormones expression in new world primate (Callithrix jacchus) and human pancreatic islets," General and Comparative Endocrinology, vol. 174, pp. 71-79, 2011.

[59] L. Huang and C. P. Kirschke, "A di-leucine sorting signal in ZIP1 (SLC39A1) mediates endocytosis of the protein," The FEBS Journal, vol. 274, no. 15, pp. 3986-3997, 2007.

[60] F. Wang, J. Dufner-Beattie, B.-E. Kim, M. J. Petris, G. Andrews, and D. J. Eide, "Zinc-stimulated endocytosis controls activity of the mouse ZIP1 and ZIP3 Zinc uptake transporters," The Journal of Biological Chemistry, vol. 279, no. 23, pp. 24631-24639, 2004.

[61] R. B. Franklin, P. Feng, B. Milon et al., "hZIP1 Zinc uptake transporter down regulation and Zinc depletion in prostate cancer," Molecular Cancer, vol. 4, article 32, 2005.

[62] K. W. Leung, A. Gvritishvili, Y. Liu, and J. Tombran-Tink, "ZIP2 and ZIP4 mediate age-related Zinc fluxes across the retinal pigment epithelium," Journal of Molecular Neuroscience, vol. 46, pp. 122-137, 2012.

[63] R. Giacconi, E. Muti, M. Malavolta et al., "A novel Zip2 Gln/Arg/Leu codon 2 polymorphism is associated with carotid artery disease in aging," Rejuvenation Research, vol. 11, no. 2, pp. 297-300, 2008.

[64] J. L. Peters, J. Dufner-Beattie, W. Xu et al., "Targeting of the mouse Slc39a2 (Zip2) gene reveals highly cell-specific patterns of expression, and unique functions in Zinc, iron, and calcium homeostasis," Genesis, vol. 45, no. 6, pp. 339-352, 2007.

[65] S. L. Kelleher and B. Lönnerdal, "Zip3 plays a major role in Zinc uptake into mammary epithelial cells and is regulated by prolactin," American Journal of Physiology, vol. 288, no. 5, pp. C1042-C1047, 2005.

[66] V. Yuzbasiyan-Gurkan and E. Bartlett, "Identification of a unique splice site variant in SLC39A4 in bovine hereditary Zinc deficiency, lethal trait A46: an animal model of acrodermatitis enteropathica," Genomics, vol. 88, no. 4, pp. 521-526, 2006.

[67] T. Donahue and O. J. Hines, "The ZIP4 pathway in pancreatic cancer," Cancer Biology \& Therapy, vol. 9, no. 3, pp. 243-245, 2010.
[68] F. Wang, B. E. Kim, M. J. Petris, and D. J. Eide, "The mammalian Zip5 protein is a Zinc transporter that localizes to the basolateral surface of polarized cells," The Journal of Biological Chemistry, vol. 279, no. 49, pp. 51433-51441, 2004.

[69] B. P. Weaver and G. K. Andrews, "Regulation of Zinc-responsive Slc39a5 (Zip5) translation is mediated by conserved elements in the 3'-untranslated region," BioMetals, vol. 25, pp. 319-335, 2012.

[70] K. M. Taylor, "A distinct role in breast cancer for two LIV1 family Zinc transporters," Biochemical Society Transactions, vol. 36, no. 6, pp. 1247-1251, 2008.

[71] L. Huang, C. P. Kirschke, Y. Zhang, and Y. Y. Yan, "The ZIP7 gene (Slc39a7) encodes a Zinc transporter involved in Zinc homeostasis of the Golgi apparatus," The Journal of Biological Chemistry, vol. 280, no. 15, pp. 15456-15463, 2005.

[72] K. M. Taylor, P. Vichova, N. Jordan, S. Hiscox, R. Hendley, and R. I. Nicholson, "ZIP7-mediated intracellular Zinc transport contributes to aberrant growth factor signaling in antihormone-resistant breast cancer cells," Endocrinology, vol. 149, no. 10, pp. 4912-4920, 2008.

[73] C.-Y. Wang, S. Jenkitkasemwong, S. Duarte et al., "ZIP8 is an Iron and Zinc transporter whose cell-surface expression is upregulated by cellular iron loading," The Journal of Biological Chemistry, vol. 287, pp. 34032-34043, 2012.

[74] L. He, K. Girijashanker, T. P. Dalton et al., "ZIP8, member of the solute-carrier-39 (SLC39) metal-transporter family: characterization of transporter properties," Molecular Pharmacology, vol. 70, no. 1, pp. 171-180, 2006.

[75] W. Matsuura, T. Yamazaki, Y. I. Yuko et al., "SLC39A9 (ZIP9) regulates Zinc homeostasis in the secretory pathway: characterization of the zip subfamily i protein in vertebrate cells," Bioscience, Biotechnology and Biochemistry, vol. 73, no. 5, pp. 1142-1148, 2009.

[76] N. Kagara, N. Tanaka, S. Noguchi, and T. Hirano, "Zinc and its transporter ZIP10 are involved in invasive behavior of breast cancer cells," Cancer Science, vol. 98, no. 5, pp. 692697, 2007.

[77] P. Kaler and R. Prasad, "Molecular cloning and functional characterization of novel Zinc transporter rZip10 (Slc39a10) involved in Zinc uptake across rat renal brush-border membrane," American Journal of Physiology, vol. 292, no. 1, pp. F217-F229, 2007.

[78] S. L. Kelleher, V. Velasquez, T. P. Croxford, N. H. McCormick, V. Lopez, and J. MacDavid, "Mapping the Zinc-transporting system in mammary cells: molecular analysis reveals a phenotype-dependent Zinc-transporting network during lactation," Journal of Cellular Physiology, vol. 227, pp. 1761-1770, 2012.

[79] M. Bly, "Examination of the Zinc transporter gene, SLC39A12," Schizophrenia Research, vol. 81, no. 2-3, pp. 321322, 2006.

[80] T. Fukada, N. Civic, T. Furuichi et al., “The Zinc transporter SLC39A13/ZIP13 is required for connective tissue development; its involvement in BMP/TGF- $\beta$ signaling pathways," PLoS One, vol. 3, no. 11, Article ID e3642, 2008.

[81] B. H. Bin, T. Fukada, T. Hosaka et al., "Biochemical characterization of human ZIP13 protein: a homo-dimerized Zinc transporter involved in the spondylocheiro dysplastic EhlersDanlos syndrome," The Journal of Biological Chemistry, vol. 286, pp. 40255-40265, 2011.

[82] C. Lang, C. Murgia, M. Leong et al., "Anti-inflammatory effects of Zinc and alterations in Zinc transporter mRNA in mouse models of allergic inflammation," American Journal of Physiology, vol. 292, no. 2, pp. L577-L584, 2007. 
[83] K. Girijashanker, L. He, M. Soleimani et al., "Slc39a14 gene encodes ZIP14, a metal/bicarbonate symporter: similarities to the ZIP8 transporter," Molecular Pharmacology, vol. 73, pp. 1413-1423, 2008.

[84] R. D. Palmiter, T. B. Cole, and S. D. Findley, "ZnT-2, a mammalian protein that confers resistance to Zinc by facilitating vesicular sequestration," EMBO Journal, vol. 15, no. 8, pp. 1784-1791, 1996.

[85] R. D. Palmiter, T. B. Cole, C. J. Quaife, and S. D. Findley, "ZnT-3, a putative transporter of Zinc into synaptic vesicles," Proceedings of the National Academy of Sciences of the United States of America, vol. 93, no. 25, pp. 14934-14939, 1996.

[86] N. Beyer, D. T. R. Coulson, S. Heggarty et al., "ZnT3 mRNA levels are reduced in Alzheimer's disease post-mortem brain,” Molecular Neurodegeneration, vol. 4, article 53, 2009.

[87] L. Huang and J. Gitschier, "A novel gene involved in Zinc transport is deficient in the lethal milk mouse," Nature Genetics, vol. 17, no. 3, pp. 292-297, 1997.

[88] K. Inoue, K. Matsuda, M. Itoh et al., "Osteopenia and malespecific sudden cardiac death in mice lacking a Zinc transporter gene, Znt5," Human Molecular Genetics, vol. 11, no. 15, pp. 1775-1784, 2002.

[89] C. P. Kirschke and L. Huang, "ZnT7, a novel mammalian Zinc transporter, accumulates Zinc in the Golgi apparatus," The Journal of Biological Chemistry, vol. 278, no. 6, pp. 40964102, 2003.

[90] S. Tepaamorndech, L. Huang, and C. P. Kirschke, "A nullmutation in the Znt7 gene accelerates prostate tumor formation in a transgenic adenocarcinoma mouse prostate model," Cancer Letters, vol. 308, pp. 33-42, 2011.

[91] J. Xu, J. Wang, and B. Chen, "SLC30A8 (ZnT8) variations and type 2 diabetes in the Chinese Han population," Genetics and Molecular Research, vol. 11, pp. 1592-1598, 2012.

[92] J. M. Howson, S. Krause, H. Stevens et al., "Genetic association of Zinc transporter 8 (ZnT8) autoantibodies in type 1 diabetes cases," Diabetologia, vol. 55, pp. 1978-1984, 2012.

[93] D. L. C. Sim and V. T. K. Chow, "The novel human HUEL (C4orf1) gene maps to chromosome 4p12-p13 and encodes a nuclear protein containing the nuclear receptor interaction motif," Genomics, vol. 59, no. 2, pp. 224-233, 1999.

[94] M. Stamelou, K. Tuschl, W. K. Chong et al., "Dystonia with brain manganese accumulation resulting from SLC30A10 mutations: a new treatable disorder," Movement Disorders, vol. 27, pp. 1317-1322, 2012.

[95] K. Tuschl, P. T. Clayton, S. M. Gospe Jr. et al., "Syndrome of hepatic cirrhosis, dystonia, polycythemia, and hypermanganesemia caused by mutations in SLC30A10, a manganese transporter in man," American Journal of Human Genetics, vol. 90, pp. 457-466, 2012.

[96] M. Quadri, A. Federico, T. Zhao et al., "Mutations in SLC30A10 cause parkinsonism and dystonia with hypermanganesemia, polycythemia, and chronic liver disease," American Journal of Human Genetics, vol. 90, pp. 467-477, 2012.

[97] R. D. Andersen, B. W. Birren, T. Ganz, J. E. Piletz, and H. R. Herschman, "Molecular cloning of the rat metallothionein 1 (MT-1) mRNA sequence," DNA, vol. 2, no. 1, pp. 15-22, 1983.

[98] M. Levadoux-Martin, J. E. Hesketh, J. H. Beattie, and H. M. Wallace, "Influence of metallothionein-1 localization on its function," The Biochemical Journal, vol. 355, no. 2, pp. 473479, 2001.

[99] H. Kurita, S. Ohsako, S. I. Hashimoto, J. Yoshinaga, and C. Tohyama, "Prenatal Zinc deficiency-dependent epigenetic alterations of mouse metallothioneins-2 gene," The Journal of Nutrional Biochemistry, vol. 24, no. 1, pp. 256-266, 2013.

[100] A. Santon, G. C. Sturniolo, V. Albergoni, and P. Irato, "Metallothionein-1 and metallothionein-2 gene expression and localisation of apoptotic cells in Zn-treated LEC rat liver," Histochemistry and Cell Biology, vol. 119, no. 4, pp. 301-308, 2003.

[101] Y. Manso, J. Carrasco, G. Comes et al., "Characterization of the role of metallothionein-3 in an animal model of Alzheimer's disease," Cellular and Molecular Life Sciences, vol. 69, pp. 3683-3700, 2012.

[102] H. I. Chen, Y. W. Chiu, Y. K. Hsu, W. F. Li, Y. C. Chen, and H. Y. Chuang, "The association of metallothionein-4 gene polymorphism and renal function in long-term lead-exposed workers," Biological Trace Element Research, vol. 137, no. 1, pp. 55-62, 2010.

[103] G. Meloni, K. Zovo, J. Kazantseva, P. Palumaa, and M. Vašák, "Organization and assembly of metal-thiolate clusters in epithelium-specific metallothionein-4," The Journal of Biological Chemistry, vol. 281, no. 21, pp. 14588-14595, 2006.

[104] L. A. Gaither and D. J. Eide, "Eukaryotic Zinc transporters and their regulation," BioMetals, vol. 14, no. 3-4, pp. 251270, 2001.

[105] S. Yamasaki, K. Sakata-Sogawa, A. Hasegawa et al., "Zinc is a novel intracellular second messenger," The Journal of Cell Biology, vol. 177, no. 4, pp. 637-645, 2007.

[106] T. Hirano, M. Murakami, T. Fukada, K. Nishida, S. Yamasaki, and T. Suzuki, "Roles of Zinc and Zinc signaling in immunity: Zinc as an intracellular signaling molecule," in Advances in Immunology, W. A. Frederick, Ed., vol. 97, pp. 149-176, Academic Press, 2008.

[107] L. Coulston and P. Dandona, "Insulin-like effect of Zinc on adipocytes," Diabetes, vol. 29, no. 8, pp. 665-667, 1980.

[108] J. M. May and C. S. Contoreggi, "The mechanism of the insulin-like effects of ionic Zinc," The Journal of Biological Chemistry, vol. 257, no. 8, pp. 4362-4368, 1982.

[109] O. Ezaki, "IIb group metal ions $(\mathrm{Zn} 2+, \mathrm{Cd} 2+, \mathrm{Hg} 2+)$ stimulate glucose transport activity by post-insulin receptor kinase mechanism in rat adipocytes," The Journal of Biological Chemistry, vol. 264, no. 27, pp. 16118-16122, 1989.

[110] X. H. Tang and N. F. Shay, "Zinc has an insulin-like effect on glucose transport mediated by phosphoinositol-3-kinase and Akt in 3T3-L1 fibroblasts and adipocytes," The Journal of Nutrition, vol. 131, no. 5, pp. 1414-1420, 2001.

[111] H. Haase and W. Maret, "Fluctuations of cellular, available Zinc modulate insulin signaling via inhibition of protein tyrosine phosphatases," Journal of Trace Elements in Medicine and Biology, vol. 19, no. 1, pp. 37-42, 2005.

[112] Y.-M. Ma, R.-Y. Tao, Q. Liu et al., "PTP1B inhibitor improves both insulin resistance and lipid abnormalities in vivo and in vitro," Molecular and Cellular Biochemistry, vol. 357, pp. 6572, 2011.

[113] B. Xue, Y.-B. Kim, A. Lee et al., "Protein-tyrosine phosphatase $1 \mathrm{~B}$ deficiency reduces insulin resistance and the diabetic phenotype in mice with polygenic insulin resistance," The Journal of Biological Chemistry, vol. 282, no. 33, pp. 2382923840, 2007.

[114] A. González-Rodríguez, J. A. M. Gutierrez, S. Sanz-González, M. Ros, D. J. Burks, and Á. M. Valverde, "Inhibition of PTP1B restores IRS1-mediated hepatic insulin signaling in IRS2deficient mice," Diabetes, vol. 59, no. 3, pp. 588-599, 2010.

[115] R. Ilouz, O. Kaidanovich, D. Gurwitz, and H. Eldar-Finkelman, "Inhibition of glycogen synthase kinase- $3 \beta$ by 
bivalent Zinc ions: insight into the insulin-mimetic action of Zinc," Biochemical and Biophysical Research Communications, vol. 295, no. 1, pp. 102-106, 2002.

[116] T. Moniz, M. J. Amorim, R. Ferreira et al., "Investigation of the insulin-like properties of Zinc(II) complexes of 3-hydrox$y$-4-pyridinones: identification of a compound with glucose lowering effect in STZ-induced type I diabetic animals," Journal of Inorganic Biochemistry, vol. 105, pp. 1675-1682, 2011.

[117] S. F. Simon and C. G. Taylor, "Dietary Zinc supplementation attenuates hyperglycemia in $\mathrm{db} / \mathrm{db}$ mice," Proceedings of the Society for Experimental Biology and Medicine, vol. 226, no. 1, pp. 43-51, 2001.

[118] N. Wijesekara, F. Chimienti, and M. B. Wheeler, "Zinc, a regulator of islet function and glucose homeostasis," Diabetes, Obesity and Metabolism, vol. 11, no. 4, pp. 202-214, 2009.

[119] Y. Yoshikawa, E. Ueda, Y. Kojima, and H. Sakurai, "The action mechanism of Zinc(II) complexes with insulinomimetic activity in rat adipocytes," Life Sciences, vol. 75, no. 6, pp. 741-751, 2004.

[120] Y. Zhao, Y. Tan, J. Dai et al., "Zinc deficiency exacerbates diabetic down-regulation of Akt expression and function in the testis: essential roles of PTEN, PTP1B and TRB3," The Journal of Nutritional Biochemistry, vol. 23, no. 8, pp. 10181026, 2012.

[121] N. R. Pandey, G. Vardatsikos, M. Z. Mehdi, and A. K. Srivastava, "Cell-type-specific roles of IGF-1R and EGFR in mediating $\mathrm{Zn}^{2+}$-induced ERK1/2 and PKB phosphorylation," Journal of Biological Inorganic Chemistry, vol. 15, no. 3, pp. 399-407, 2010.

[122] J. C. Rutherford and A. J. Bird, "Metal-responsive transcription factors that regulate Iron, Zinc, and Copper homeostasis in eukaryotic cells," Eukaryotic Cell, vol. 3, no. 1, pp. 1-13, 2004.

[123] I. Hwang, T. Yoon, C. Kim, B. Cho, S. Lee, and M. K. Song, "Different roles of Zinc plus arachidonic acid on insulin sensitivity between high fructose- and high fat-fed rats," Life Sciences, vol. 88, no. 5-6, pp. 278-284, 2011.

[124] K. F. Petersen, S. Dufour, D. B. Savage et al., "The role of skeletal muscle insulin resistance in the pathogenesis of the metabolic syndrome," Proceedings of the National Academy of Sciences of the United States of America, vol. 104, no. 31, pp. 12587-12594, 2007.

[125] M. Peppa, C. Koliaki, P. Nikolopoulos, and S. A. Raptis, "Skeletal muscle insulin resistance in endocrine disease," Journal of Biomedicine and Biotechnology, vol. 2010, Article ID 527850, 13 pages, 2010.

[126] Y. A. Seo, V. Lopez, and S. L. Kelleher, "A histidine-rich motif mediates mitochondrial localization of ZnT2 to modulate mitochondrial function," American Journal of Physiology, vol. 300, no. 6, pp. C1479-C1489, 2011.

[127] J. P. Liuzzi, R. K. Blanchard, and R. J. Cousins, "Differential regulation of Zinc transporter 1, 2, and 4 mRNA expression by dietary Zinc in rats," The Journal of Nutrition, vol. 131, no. 1, pp. 46-52, 2001.

[128] F. Radtke, R. Heuchel, O. Georgiev et al., "Cloned transcription factor MTF-1 activates the mouse metallothionein I promoter," EMBO Journal, vol. 12, no. 4, pp. 1355-1362, 1993.

[129] S. J. Langmade, R. Ravindra, P. J. Daniels, and G. K. Andrews, "The transcription factor MTF-1 mediates metal regulation of the mouse ZnT1 gene," The Journal of Biological Chemistry, vol. 275, no. 44, pp. 34803-34809, 2000.
[130] R. A. Cragg, G. R. Christie, S. R. Phillips et al., "A novel Zincregulated human Zinc transporter, hZTL1, is localized to the enterocyte apical membrane," The Journal of Biological Chemistry, vol. 277, no. 25, pp. 22789-22797, 2002.

[131] L. C. Costellot, Y. Liu, J. Zou, and R. B. Franklin, "Evidence for a Zinc uptake transporter in human prostate cancer cells which is regulated by prolactin and testosterone," The Journal of Biological Chemistry, vol. 274, no. 25, pp. 17499-17504, 1999.

[132] K. M. Taylor, H. E. Morgan, K. Smart et al., "The emerging role of the LIV-1 subfamily of Zinc transporters in breast cancer," Molecular Medicine, vol. 13, no. 7-8, pp. 396-406, 2007.

[133] B. Besecker, S. Bao, B. Bohacova, A. Papp, W. Sadee, and D. L. Knoell, "The human Zinc transporter SLC39A8 (Zip8) is critical in Zinc-mediated cytoprotection in lung epithelia," American Journal of Physiology, vol. 294, no. 6, pp. L1127L1136, 2008.

[134] J. R. Napolitano, M.-J. Liu, S. Bao et al., "Cadmium-mediated toxicity of lung epithelia is enhanced through NFêB-mediated transcriptional activation of the human Zinc transporter ZIP8," American Journal of Physiology, vol. 302, pp. L909-L918, 2012.

[135] J. P. Liuzzi, L. A. Lichten, S. Rivera et al., "Interleukin-6 regulates the Zinc transporter Zip14 in liver and contributes to the hypoZincemia of the acute-phase response," Proceedings of the National Academy of Sciences of the United States of America, vol. 102, no. 19, pp. 6843-6848, 2005.

[136] M. Lazarczyk, C. Pons, J.-A. Mendoza, P. Cassonnet, Y. Jacob, and M. Favre, "Regulation of cellular Zinc balance as a potential mechanism of EVER-mediated protection against pathogenesis by cutaneous oncogenic human papillomaviruses," The Journal of Experimental Medicine, vol. 205, no. 1, pp. 3542, 2008 .

[137] B.-E. Kim, F. Wang, J. Dufner-Beattie, G. K. Andrews, D. J. Eide, and M. J. Petris, " $\mathrm{Zn}^{2+}$-stimulated endocytosis of the mZIP4 Zinc transporter regulates its location at the plasma membrane," The Journal of Biological Chemistry, vol. 279, no. 6, pp. 4523-4530, 2004.

[138] T. Suzuki, K. Ishihara, H. Migaki et al., "Zinc transporters, ZnT5 and ZnT7, are required for the activation of alkaline phosphatases, Zinc-requiring enzymes that are glycosylphosphatidylinositol-anchored to the cytoplasmic membrane," The Journal of Biological Chemistry, vol. 280, no. 1, pp. 637-643, 2005.

[139] B. Milon, D. Dhermy, D. Pountney, M. Bourgeois, and C. Beaumont, "Differential subcellular localization of hZip1 in adherent and non-adherent cells," FEBS Letters, vol. 507, no. 3, pp. 241-246, 2001.

[140] K. M. Taylor, S. Hiscox, R. I. Nicholson, C. Hogstrand, and P. Kille, "Protein kinase CK2 triggers cytosolic Zinc signaling pathways by phosphorylation of Zinc channel ZIP7," Science Signaling, vol. 5, article 11, 2012.

[141] R. Meng, C. Götz, and M. Montenarh Mathias, "The role of protein kinase CK2 in the regulation of the insulin production of pancreatic islets," Biochemical and Biophysical Research Communications, vol. 401, no. 2, pp. 203-206, 2010.

[142] C. Taghibiglou, F. Rashid-Kolvear, S. C. Van Iderstine et al., "Hepatic very low density lipoprotein-ApoB overproduction is associated with attenuated hepatic insulin signaling and overexpression of protein-tyrosine phosphatase $1 \mathrm{~B}$ in a fructose-fed hamster model of insulin resistance," The Journal of Biological Chemistry, vol. 277, no. 1, pp. 793-803, 2002. 
[143] A. R. Saltiel and J. E. Pessin, "Insulin signaling pathways in time and space," Trends in Cell Biology, vol. 12, no. 2, pp. 65$71,2002$.

[144] S. Hojyo, T. Fukada, S. Shimoda et al., "The Zinc transporter SLC39A14/ZIP14 controls G-protein coupled receptormediated signaling required for systemic growth," PLoS One, vol. 6, no. 3, Article ID e18059, 2011.

[145] S. Tang, H. Le-Tien, B. J. Goldstein, P. Shin, R. Lai, and I. G. Fantus, "Decreased in situ insulin receptor dephosphorylation in hyperglycemia-induced insulin resistance in rat adipocytes," Diabetes, vol. 50, no. 1, pp. 83-90, 2001.

[146] M. K. Song, M. J. Rosenthal, S. Hong et al., "Synergistic antidiabetic activities of Zinc, cyclo (his-pro), and arachidonic acid," Metabolism, vol. 50, no. 1, pp. 53-59, 2001.

[147] J. H. Y. Park, C. J. Grandjean, M. H. Hart, S. H. Erdman, P. Pour, and J. A. Vanderhoof, "Effect of pure Zinc deficiency on glucose tolerance and insulin and glucagon levels," American Journal of Physiology, vol. 251, no. 3, p. 14/3, 1986.

[148] R. Jayawardena, P. Ranasinghe, P. Galappatthy, R. Malkanthi, G. Constantine, and P. Katulanda, "Effects of Zinc supplementation on diabetes mellitus: a systematic review and meta-analysis," Diabetology \& Metabolic Syndrome, vol. 4, article 13, 2012.

[149] J. M. Wenzlau, K. Juhl, L. Yu et al., "The cation efflux transporter $\mathrm{ZnT}$ (Slc30A8) is a major autoantigen in human type 1 diabetes," Proceedings of the National Academy of Sciences of the United States of America, vol. 104, no. 43, pp. 1704017045, 2007.

[150] Y. Fu, W. Tian, E. B. Pratt et al., "Down-regulation of ZnT8 expression in INS-1 rat pancreatic beta cells reduces insulin content and glucose-inducible insulin secretion," PLoS One, vol. 4, no. 5, Article ID e5679, 2009.

[151] N. Wijesekara, F. F. Dai, A. B. Hardy et al., "Beta cell-specific Znt8 deletion in mice causes marked defects in insulin processing, crystallisation and secretion," Diabetologia, vol. 53, no. 8, pp. 1656-1668, 2010.

[152] T. J. Nicolson, E. A. Bellomo, N. Wijesekara et al., "Insulin storage and glucose homeostasis in mice null for the granule Zinc transporter ZnT8 and studies of the type 2 diabetesassociated variants," Diabetes, vol. 58, no. 9, pp. 2070-2083, 2009.

[153] L. D. Pound, S. A. Sarkar, R. K. P. Benninger et al., "Deletion of the mouse Slc30a8 gene encoding Zinc transporter-8 results in impaired insulin secretion," The Biochemical Journal, vol. 421, no. 3, pp. 371-376, 2009.

[154] A. B. Hardy, N. Wijesekara, I. Genkin et al., "Effects of highfat diet feeding on Znt8-null mice: differences between betacell and global knockout of Znt8," American Journal of Physiology, vol. 302, pp. E1084-E1096, 2012.

[155] R. Sladek, G. Rocheleau, J. Rung et al., "A genome-wide association study identifies novel risk loci for type 2 diabetes," Nature, vol. 445, no. 7130, pp. 881-885, 2007.

[156] J. Xu, J. Wang, and B. Chen, "SLC30A8 (ZnT8) variations and type 2 diabetes in the Chinese Han population," Genetics and Molecular Research, vol. 11, pp. 1592-1598, 2012.

[157] R. Saxena, B. F. Voight, V. Lyssenko et al., "Genome-wide association analysis identifies loci for type 2 diabetes and triglyceride levels," Science, vol. 316, pp. 1331-1336, 2007.

[158] T. W. Boesgaard, J. Žilinskaite, M. Vänttinen et al., "The common SLC30A8 Arg325Trp variant is associated with reduced first-phase insulin release in 846 non-diabetic offspring of type 2 diabetes patients-The EUGENE2 study," Diabetologia, vol. 51, no. 5, pp. 816-820, 2008.
[159] L. Huang, M. Yan, and C. P. Kirschke, "Over-expression of ZnT7 increases insulin synthesis and secretion in pancreatic $\beta$-cells by promoting insulin gene transcription," Experimental Cell Research, vol. 316, no. 16, pp. 2630-2643, 2010.

[160] L. Huang, C. P. Kirschke, Y.-A. E. Lay, L. B. Levy, D. E. Lamirande, and P. H. Zhang, "Znt7-null mice are more susceptible to diet-induced glucose intolerance and insulin resistance," The Journal of Biological Chemistry, vol. 287, pp. 3388333896, 2012.

[161] K. Smidt, N. Jessen, A. B. Petersen et al., "SLC30A3 responds to glucose- and Zinc variations in $\beta$-cells and is critical for insulin production and in vivo glucose-metabolism during $\beta$-cell stress," PLoS One, vol. 4, no. 5, Article ID e5684, 2009.

[162] E. A. Bellomo, G. Meur, and G. A. Rutter, "Glucose regulates free cytosolic Zn2+ concentration, Slc39 (ZiP), and metallothionein gene expression in primary pancreatic islet $\beta$ cells," The Journal of Biological Chemistry, vol. 286, no. 29, pp. 25778-25789, 2011. 


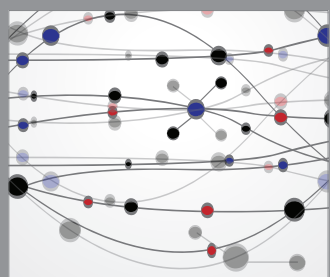

The Scientific World Journal
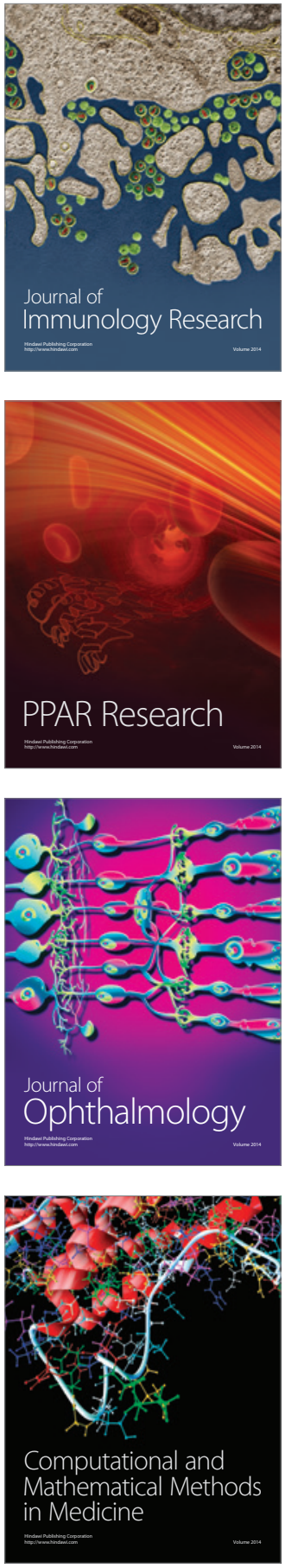

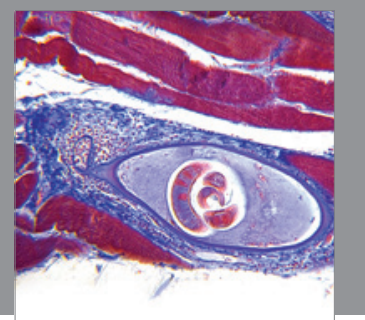

Gastroenterology

Research and Practice
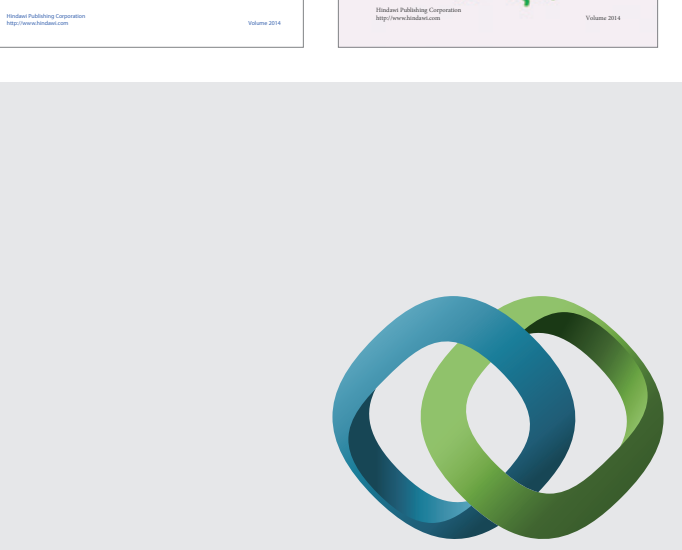

\section{Hindawi}

Submit your manuscripts at

http://www.hindawi.com
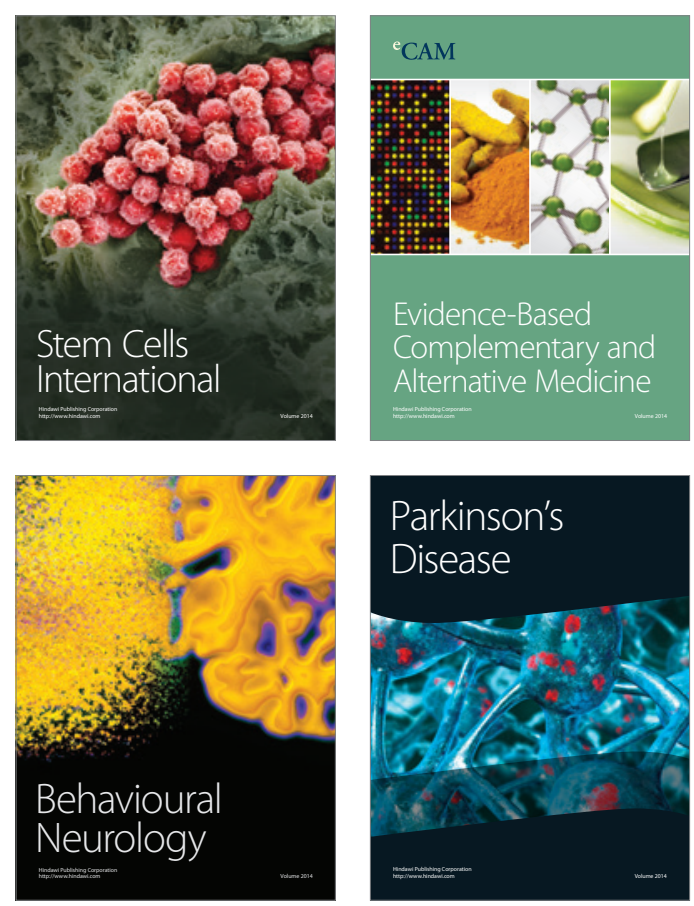

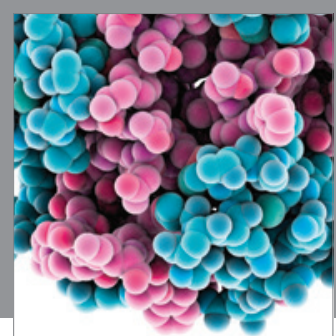

Journal of
Diabetes Research

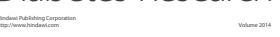

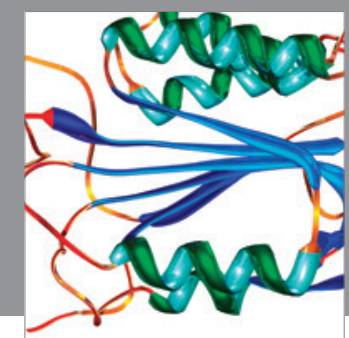

Disease Markers
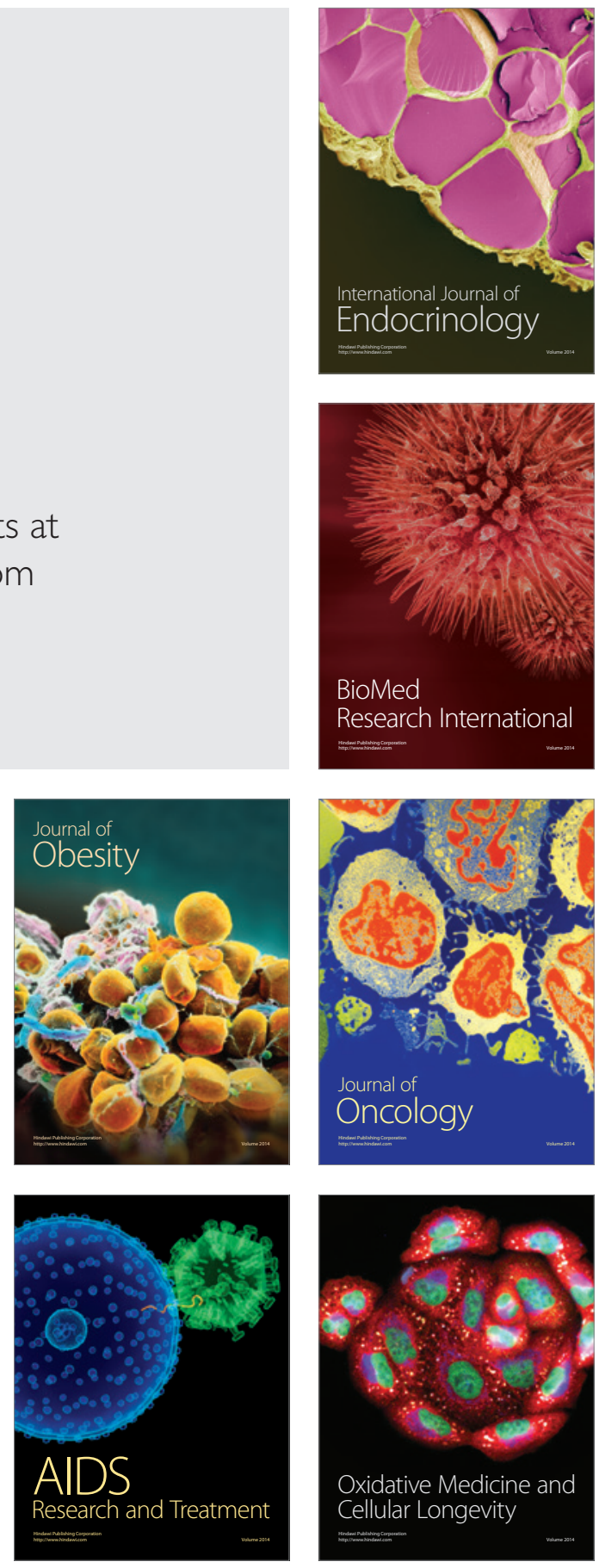